who spoke on Embeddings of $(n-1)$-spheres in $n$-space. Professor J. A. Cima introduced Professor James D. Buckholtz of the University of Kentucky who spoke on Strong convergence and polynomial expansions of analytic functions. Professor D. R. McMillan introduced Professor William Jaco of Rice University who spoke on 3-manifold groups-A survey.

By invitation of the same committee there were three special sessions organized by Professors R. Hodel, Eugene M. Norris and John Burns, respectively.

There were six sessions for contributed papers which were chaired by Professors Jimmy Arnold, R. Dickman, William Greenberg, Douglas L. Casta, J. A. Cochran and R. McCoy.

There was a beer party held on Friday evening from 8:00 p.m. until midnight for members of the Society and their guests.

TAllahassee, Florida

O. G. HARRold

Associate Secretary

\title{
THE NOVEMBER MEETING IN LOS ANGELES
}

The seven hundred thirtieth meeting of the American Mathematical Society was held at the University of California, Los Angeles, California, on Saturday, November 15, 1975. There were 134 registrants including 115 members of the Society. There was also a concurrent meeting of the Association for Women in Mathematics.

By invitation of the Committee to Select Hour Speakers for Far Western Sectional Meetings, there were two invited hour addresses. Professor Robert Osserman, Stanford University, lectured on The isoperimetric inequality; he was introduced by Professor Nathaniel Grossman. Professor Jerry L. Kazdan, University of California, Berkeley and University of Pennsylvania, spoke on Applications of partial differential equations to differential geometry. Professor James H. White introduced Professor Kazdan.

There were two special sessions of selected twenty-minute papers. Professor Theodore W. Gamelin of the University of California, Los Angeles, organized a special session on Function Algebras and Related Areas. The speakers were Alice Chang, Irving L. Glicksberg, Donald E. Marshall, Donald E. Sarason, David A. Stegenga, Joseph L. Taylor, and James Li-Ming Wang. Professor Nathaniel Grossman of the University of California, Los Angeles, organized a special session on Differential Geometry. The speakers were John T. Burns, James B. Carrell, Mark Green, Stefan Hildebrandt, William Meeks, and Joel L. Weiner.

There were two sessions of contributed ten-minute papers chaired by Professors Charles W. Austin and Garry D. Hart.

Eugene, OREgon

Kenneth A. Ross Associate Secretary 